\section{3-D Dynamic Modeling and Validation of Human Arm for Torque Determination During Eating Activity Using Kane's Method}

By: Hussain, Z (Hussain, Zakia) ${ }^{[1]}$; Azlan, NZ (Azlan, Norsinnira Zainul) ${ }^{[1]}$

View Web of Science ResearcherID and ORCID

IRANIAN JOURNAL OF SCIENCE AND TECHNOLOGY-TRANSACTIONS OF MECHANICAL ENGINEERING

Volume: 44 Issue: 3 Pages: 661-694

DOI: $10.1007 / \mathrm{s} 40997-019-00299-8$

Published: SEP 2020

Document Type: Article

View Journal Impact

\section{Abstract}

Upper limb disability is one of the major adversities faced by post-stroke patients. Eating is one of the fundamental activities of survival for all living beings. The robotic rehabilitation systems for people with upper limb disabilities must have the capability of assisting the patients, providing appropriate forces/torques, during various eating activities. In this study, a 3-D, four-DOF dynamic, mathematical model of human arm, including wrist and elbow joints, focusing on elbow flexion/extension motion, forearm pronation/supination, wrist flexion/extension and wrist adduction/abduction is formulated, for predicting the torques during different eating activities. A simulation study and experimental validation has been conducted involving five different food types and using two types of cutlery, which are, a fork and a spoon, to study their effect on the corresponding torques produced. It was observed that the maximum torque is obtained in both wrist and elbow joint when the subject digs into the food and eats (event B) in the majority of the eating tasks. The accuracy of the model, in terms of torque prediction, was compared to that of the load cell, for all eating activities, using RMSE as a statistical measure, to the test the performance of the model. The results indicate that 3-D dynamic model formulated fits all the torques for all eating activities very well, with the average RMSE of $0.05 \mathrm{Nm}$ and the performance of the model is good. These results verify that the proposed Kane's model, successfully models the HUL, during different eating tasks and using different types of cutlery.

\section{Keywords}

Author Keywords: Dynamic modeling; Wrist; Elbow; Eating; Kane's method; RMSE

KeyWords Plus: BIOMECHANICAL MODEL; UPPER EXTREMITY; STROKE; WRIST; HAND; RMSE

\section{Author Information}

Reprint Address:

International Islamic University Malaysia Int Islamic Univ Malaysia, Dept Mechatron Engn, Kuala Lumpur 53100 , Selangor, Malaysia.

Corresponding Address: Azlan, NZ (corresponding author)

+ Int Islamic Univ Malaysia, Dept Mechatron Engn, Kuala Lumpur 53100, Selangor, Malaysia.

Addresses:

+ [1] Int Islamic Univ Malaysia, Dept Mechatron Engn, Kuala Lumpur 53100, Selangor, Malaysia

E-mail Addresses: sinnira@iium.edu.my

Publisher

SPRINGER, ONE NEW YORK PLAZA, SUITE 4600, NEW YORK, NY, UNITED STATES

Journal Information

Impact Factor: Journal Citation Reports

Categories / Classification

Research Areas: Engineering

Web of Science Categories: Engineering, Mechanical

See more data fields

\section{Citation Network}

In Web of Science Core Collection

0

Times Cited

Create Citation Alert

\section{5}

Cited References

View Related Records

(i) New! You may also like ... ${ }^{\text {BETA }}$

A self-training numerical method to calculate the magnetic characteristics for switched reluctance motor drives. IEEE TRANSACTIONS ON MAGNETICS (2004

Dynamic modelling of a railway wheelset based on Kane's method. INTERNATIONAL JOURNAL OF HEAVY VEHICLE SYSTEMS (2020)

A Robot Arm Actuated by Mckibben Muscles.

MECHANICAL, MATERIALS AND MANUFACTURING ENGINEERING, PTS 1-3 (2011)

Modeling and Simulation of Robot Inverse Dynamics Using LSTM-Based Deep Learning Algorithm for Smart Cities and Factories. IEEE ACCESS (2019)

Human Upper limb and Arm Kinematics for Robot based Rehabilitation. 2009 IEEE/ASME INTERNATIONAL CONFERENCE ON ADVANCED INTELLIGENT MECHATRONICS, VOLS 1-3 (2009)

View all suggestions

\section{Use in Web of Science}

Web of Science Usage Count

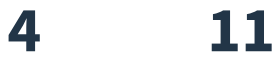

Last 180 Days $\quad$ Since 2013

Learn more

\section{This record is from:}

Web of Science Core Collection

- Science Citation Index Expanded

\section{Suggest a correction}

If you would like to improve the quality of the data in this record, please suggest a correction. 


\section{Cited References: 45}

1. Prediction of above-elbow motions in amputees, based on electromyographic (EMG) signals, using nonlinear autoregressive exogenous (NARX) model

By: Akbari, AA; Talasaz, M.

Iran J Med Phys Volume: 11 Issue: 2-3 Pages: 233-241 Published: 2014

2. Shoulder's Modeling via Kane's Method: Determination of Torques in Smash Activity

By: Ariff, F. H. M.; Rambely, A. S.; Ghani, N. A. A

5TH KUALA LUMPUR INTERNATIONAL CONFERENCE ON BIOMEDICAL ENGINEERING 2011 (BIOMED 2011) Book Series: IFMBE Proceedings

Volume: 35 Pages: 207 -+ Published: 2011

3. Determination of torques at upper limb joints during jumping in badminton smash via Kane's method

Times Cited: 1

By: Ariff, FHM; Rambely, AS.

thod. In: ISBS-Conference proceedings archive, vol 1, No. 1 Volume: 1 Published: 2005

No. 1

4. CORRESPONDENCE AMONG THE CORRELATION, RMSE, AND HEIDKE FORECAST VERIFICATION MEASURES - REFINEMENT OF THE HEIDKE SCORE

By: BARNSTON, AG

WEATHER AND FORECASTING Volume: 7 Issue: 4 Pages: 699-709 Published: DEC 1992

5. A recursive Newton-Euler algorithm for robots with elastic joints and its application to control

Times Cited: 16

By: Buondonno, Gabriele; De Luca, Alessandro

2015 IEEE/RSJ INTERNATIONAL CONFERENCE ON INTELLIGENT ROBOTS AND SYSTEMS (IROS) Book Series: IEEE International

Conference on Intelligent Robots and Systems Pages: 5526-5532 Published: 2015

6. Upper Limb Strength Estimation of Physically Impaired Persons using a Musculoskeletal Model: A Sensitivity Analysis

By: Carmichael, Marc G.; Liu, Dikai

2015 37TH ANNUAL INTERNATIONAL CONFERENCE OF THE IEEE ENGINEERING IN MEDICINE AND BIOLOGY SOCIETY (EMBC) Book Series: IEEE Engineering in Medicine and Biology Society Conference Proceedings Pages: 2438-2441 Published: 2015

7. Root mean square error (RMSE) or mean absolute error (MAE)? - Arguments against avoiding RMSE in the literature By: Chai, T.; Draxler, R. R.

GEOSCIENTIFIC MODEL DEVELOPMENT Volume: 7 Issue: 3 Pages: 1247-1250 Published: 2014

8. Modeling of Human Arm Movement: A Study on Daily Movement

By: Choudhury, T.T.; Rahman, M.M.; Khorshidtalab, A.; et al.

2013 Fifth International Conference on Computational Intelligence, Modelling and Simulation (CIMSim) Pages: 63-8 Published: 2013

9. Adjustments to Zatsiorsky-Seluyanov's segment inertia parameters

By: de Leva, $P$

JOURNAL OF BIOMECHANICS Volume: 29 Issue: 9 Pages: 1223-1230 Published: SEP 1996

10. Kinematic analysis of the daily activity of drinking from a glass in a population with cervical spinal cord injury

2015 3RD RSI INTERNATIONAL CONFERENCE ON ROBOTICS AND MECHATRONICS (ICROM) Book Series: RSI International Conference on Robotics and Mechatronics ICRoM Pages: 444-448 Published: 2015

12. Upper Extremity Function in Stroke Subjects: Relationships between the International Classification of Functioning,

Disability, and Health Domains

By: Faria-Fortini, Iza; Michaelsen, Stella Maris; Cassiano, Janine Gomes; et al.

JOURNAL OF HAND THERAPY Volume: 24 Issue: 3 Pages: 257-264 Published: JUL-SEP 2011

13. How muscle architecture and moment arms affect wrist flexion-extension moments

Times Cited: 104 By: Gonzalez, RV; Buchanan, TS; Delp, SL

JOURNAL OF BIOMECHANICS Volume: 30 Issue: 7 Pages: 705-712 Published: JUL 1997

14. A Study on Human Upper-Limb Muscles Activities During Daily Upper-Limb Motions

By: Gopura, R. A. R. C.; Kiguchi, K.; Horikawa, E.

Int. J. Bioelectromagnetism Volume: 12 Issue: 2 Pages: 54-61 Published: 2010 
15. Modeling of an arm via Kane's method : an inverse dynamic approach

By: Hirza, F; Ariff, M; Rambely, AS.

Eur J Sci Res Volume: 33 Issue: 2 Pages: 358-364 Published: 2009

16. A model of the upper extremity for simulating musculoskeletal surgery and analyzing neuromuscular control

Times Cited: 548

By: Holzbaur, KRS; Murray, WM; Delp, SL

ANNALSOFBIOMEDICAL ENGINEERING Volume: 33 Issue: 6 Pages: 829-840 Published: JUN 2005

17. KANE'S Method for Dynamic Modeling

Times Cited: 4

By: Hussain, Zakia; Azlan, Norsinnira Zainul

2016 IEEE INTERNATIONAL CONFERENCE ON AUTOMATIC CONTROL AND INTELLIGENT SYSTEMS (I2CACIS) Pages: 174-179 Published: 2016

18. Human Lower Arm Analysis During Different Eating Activities

Times Cited: 3

By: Hussain, Zakia; Azian, Norsinnira Zainul

2017 IEEE 8TH CONTROL AND SYSTEM GRADUATE RESEARCH COLLOQUIUM (ICSGRC) Pages: 93-98 Published: 2017

19. Human Hand Motion Analysis during Different Eating Activities

By: Hussain, Zakia; Azlan, Norsinnira Zainul; bin Yusof, Arif Zuhairi

Times Cited: 4

APPLIED BIONICS AND BIOMECHANICS Volume: 2018 Article Number: 8567648 Published: 2018

20. Joint Torque Estimation Model of sEMG Signal for Arm Rehabilitation Device Using Artificial Neural Network Techniques By: Jali, M. H.; Izzuddin, T. A.; Bohari, Z. H.; et al.

ADVANCED COMPUTER AND COMMUNICATION ENGINEERING TECHNOLOGY Book Series: Lecture Notes in Electrical Engineering

Volume: 315 Pages: 671-682 Published: 2015

21. Predicting EMG Based Elbow Joint Torque Model Using Multiple Input ANN Neurons for Arm Rehabilitation

By: Jali, Mohd Hafiz; Izzuddin, Tarmizi Ahmad; Bohari, Zul Hasrizal; et al.

2014 UKSIM-AMSS 16TH INTERNATIONAL CONFERENCE ON COMPUTER MODELLING AND SIMULATION (UKSIM) Book Series: UKSim International Conference on Computer Modelling and Simulation Pages: 189-194 Published: 2014

22. Title: [not available]

By: Kane, TR; Levinson, D.

DYNAMICS THEORY APPL Published: 1985

Publisher: Theory and Applications, Mc-Graw-Hill Book Company

23. Mathematical model of the lower extremity joint reaction forces using Kane's method of dynamics

Times Cited: 76

By: Komistek, RD; Stiehl, JB; Dennis, DA; et al.

JOURNAL OF BIOMECHANICS Volume: 31 Issue: 2 Pages: 185-189 Published: FEB 1998

24. Effects of robot-assisted therapy on upper limb recovery after stroke: A systematic review

Times Cited: 849

By: Kwakkel, Gert; Kollen, Boudewijn J.; Krebs, Hermano I.

NEUROREHABILITATION AND NEURAL REPAIR Volume: 22 Issue: 2 Pages: 111-121 Published: MAR-APR 2008

25. Dynamic modeling of the human-computer interaction for upper limb rehabilitation robot

Times Cited: 2

By: Li, X.; Wang, X. F.

J. Software Eng. Volume: 10 Pages: 347-355 Published: 2016

26. Modeling the constraints of human hand motion

Times Cited: 122

By: Lin, J; Wu, Y; Huang, TS

WORKSHOP ON HUMAN MOTION, PROCEEDINGS Pages: 121-126 Published: 2000

27. Title: [not available]

Times Cited: 902

By: Mackay, J; Mensah, GA

The Atlas of Heart Disease and Stroke Published: 2004

Publisher: World Health Organization, Geneva, Switzerland

28. A kinematic and dynamic model of the human upper extremity

Times Cited: 1

By: Mansour, G; Mitsi, S; Bouzakis, KD

P 3 INT C MANENG IC Published: 2008

29. Newton-Euler, Lagrange and Kirchhoff formulations of rigid body dynamics: a unified approach

Times Cited: 1

By: Massa, Enrico; Vignolo, Stefano

MECCANICA Volume: 51 Issue: 8 Pages: 2019-2023 Published: AUG 2016

30. A Lagrange-based generalised formulation for the equations of motion of simple walking models By: McGrath, Michael; Howard, David; Baker, Richard

JOURNAL OF BIOMECHANICS Volume: 55 Pages: 139-143 Published: APR 112017 
